\title{
Glucose Regulation of Hydroperoxide Metabolism in Rat Intestinal Cells Stimulation of Reduced Nicotinamide Adenine Dinucleotide Phosphate Supply
}

Tak Yee Aw and Carol A. Rhoads

Department of Physiology and Biophysics, Louisiana State University Medical Center, Shreveport, Louisiana 71130

\begin{abstract}
The regulation of intestinal metabolism of $t$-butylhydroperoxide by glucose was examined in isolated enterocytes from proximal rat intestine. The basal rate of hydroperoxide elimination in control cells was $0.57 \pm 0.05 \mathrm{nmol} / \mathrm{min}$ per $10^{6}$ cells, and was increased threefold by $10 \mathrm{mM}$ exogenous glucose $\left(1.74 \pm 0.14 \mathrm{nmol} / \mathrm{min}\right.$ per $10^{6}$ cells $)$. Concurrently, cellular NADPH levels increased threefold $(1.62 \pm 0.40 \mathrm{nmol} /$ $10^{6}$ cells vs $0.57 \pm 0.14$ nmol $/ 10^{6}$ cells in controls $)$. The glucose effect was blocked by 6-aminonicotinamide and by 1,3 bis-(2-chloroethyl)1-nitrosourea, consistent with glucose stimulation of NADPH production by the pentose phosphate shunt, and of NADPH utilization for glutathione disulfide reduction. The NADPH supply rate was quantified by controlled infusions of diamide, a thiol oxidant. At diamide infusion of $0.05 \mathrm{nmol} / \mathrm{min}$ per $10^{6}$ cells, GSH and protein thiols in control cells were decreased significantly, consistent with a limited capacity for glutathione disulfide reduction. With glucose, cell GSH and protein thiols were preserved at a 10-fold higher diamide infusion which was reversed by 6-aminonicotinamide, supporting the view that glucose promotes glutathione disulfide reduction by increased NADPH supply. Collectively, the results demonstrate that intestinal metabolism of hydroperoxides subscribes to regulation by glucose availability. This responsiveness to glucose suggests that nutrient availability would be an important contributing factor in the detoxication of toxic hydroperoxides by the small intestine. (J. Clin. Invest. 1994. 94:24262434.) Key words: Intestinal hydroperoxide detoxication • diamide $\cdot$ glutathione, reduced, redox cycle $\bullet$ pentose phosphate shunt enterocytes $\cdot$ reduced nicotinamide adenine dinucleotide phosphate and hydroperoxide metabolism
\end{abstract}

\section{Introduction}

Substrate availability is one of several important cellular regulatory mechanisms in the control of metabolic pathways. As pertains to the metabolism of toxic peroxides, an increase in the supply of GSH has been shown to promote the metabolism of hydrogen and organic peroxides and attenuate peroxide-induced

Address correspondence to Tak Yee Aw, Department of Physiology and Biophysics, LSU Medical Center, 1501 Kings Highway, Shreveport, LA 71130.

Received for publication 17 February 1994 and in revised form 11 July 1994.

J. Clin. Invest.

(C) The American Society for Clinical Investigation, Inc. 0021-9738/94/12/2426/09 \$2.00

Volume 94, December 1994, 2426-2434 cytotoxicity in a variety of adult mammalian cells, including renal proximal tubule cells (1), enterocytes (2), alveolar type II cells (3), endothelial cells (4), and cultured murine L1210 (5). In recent studies, we found that exogenous GSH supplementation enhances the detoxication of luminal lipid hydroperoxides by rat small intestine in vivo $(6,7)$. Taken together, these findings suggest that the availability of GSH would control the ultimate metabolic fate of hydroperoxides and the vulnerability of the small intestine to oxidant injury.

In the reduction of hydroperoxides, a key step in supplying GSH to support GSH peroxidase function in the redox cycle is the regeneration of GSH from glutathione disulfide (GSSG) ${ }^{1}$ $(8,9$, Fig. 1). As illustrated in Fig. 1, the reduction of GSSG occurs at the expense of reduced NADPH. During high rates of hydroperoxide metabolism, the increased demand for NADPH could be rate limited by the pentose phosphate shunt activity $(8-10)$. This means that the overall efficiency in maintaining high mucosal GSH for the redox cycle function in the metabolism of hydroperoxides by the small intestine may largely be governed by the availability of glucose. These considerations are important since the small intestinal epithelium is often subjected to high luminal lipid hydroperoxide levels resulting from dietary consumption of polyunsaturated fats, and to large variations in luminal and plasma glucose concentrations consequent to varied dietary carbohydrate intakes.

The objectives of the current study are, therefore, to evaluate the role of glucose in the intestinal metabolism of hydroperoxides, to define the stimulation of hydroperoxide metabolism by glucose in terms of increased NADPH supply, and to quantify the NADPH supply rate. To address the objectives, isolated enterocytes were used as the cell model and $t$-butylhydroperoxide $(t \mathrm{BH})$ as a model peroxide substrate. The results provide important insights into understanding the relationship between glucose stimulation of pentose phosphate shunt activity with enhanced intestinal detoxication of hydroperoxides. More generally, the study provides evidence for a direct integration of carbohydrate metabolism with intestinal drug reduction and underscores a potential benefit of nutrient supplementation in the promotion of peroxide detoxication in the small intestine.

\section{Methods}

Enterocyte isolation. Male Sprague Dawley rats weighing between 250 and $300 \mathrm{~g}$ were used for enterocyte preparation. Routinely, the animals have access to water and chow ad lib. In all experiments, intestinal cells were isolated from fed animals except in studies of nutritional status on hydroperoxide metabolism (Fig. 3) where cells were also prepared from 24-h fasted rats. Enterocytes were isolated from the proximal

1. Abbreviations used in this paper: $\mathrm{BCNU}$, bis chloroethyl nitrosourea; GSSG, glutathione disulfide; 6-AN, 6-amino nicotinamide; $t$-BH, tertbutylhydroperoxide. 


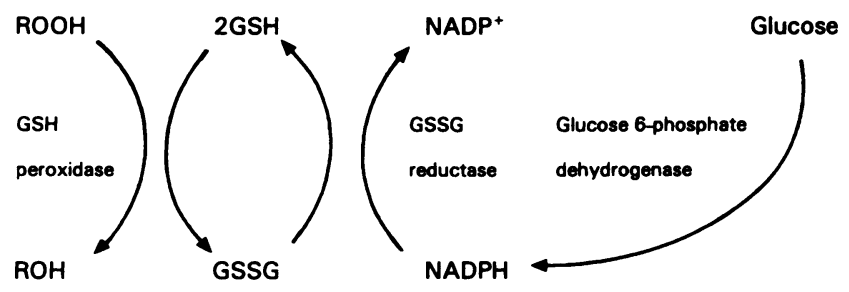

Figure 1. Glutathione redox cycle in hydroperoxide metabolism.

intestine according to Masola and Evered (11). Briefly, rats were killed under halothane anesthesia, and the proximal half of the small intestine was excised. The intestinal lumen was washed twice with cold $0.9 \%$ saline to remove particulate matter. The lumen was filled with KrebsHenseleit buffer, $\mathrm{pH} 7.4$, containing $10 \mathrm{mM}$ DTT and incubated at $37^{\circ} \mathrm{C}$ for $10 \mathrm{~min}$ to remove excess mucus. The lumen was then refilled with buffer containing $5 \mathrm{mM}$ EGTA and $10 \mathrm{mM}$ DTT, and further incubated at $37^{\circ} \mathrm{C}$ for $15 \mathrm{~min}$. Thereafter, the segment was gently massaged to release the enterocytes, and the intestinal cells were filtered through two layers of gauze and washed twice with Krebs-Henseleit buffer containing $10 \mathrm{mM}$ DTT and $0.25 \%$ BSA. Enterocytes were resuspended in DTT- and BSA-free buffer to a final cell concentration of 3.5-5 $\times 10^{6}$ cells $/ \mathrm{ml}$ and stored on ice. Cell yield from the proximal intestine of a rat was typically $7.0 \times 10^{7}$ cells. Cell viability upon isolation was routinely $85-95 \%$ as assessed by the exclusion of $0.1 \%$ trypan blue. Cells kept on ice maintained their viability for at least $2 \mathrm{~h}$, and typically, the cells were used within $1 \mathrm{~h}$ of isolation.

Whenever present, the inhibitors were added to the cell suspensions on ice at the specified final concentrations as follows: 6-amino nicotinamide (6-AN), $0.5 \mathrm{mM}$; and 1,3-bis-(2-chloroethyl)1-nitrosourea (BCNU), $50 \mu$ M. 6-AN was dissolved in Krebs Henseleit buffer to give a stock solution of $25 \mathrm{mM}$ and was warmed at $37^{\circ} \mathrm{C}$ to facilitate solubility of the compound. BCNU was first dissolved in $95 \%$ ethanol and then diluted with buffer to give a stock concentration of $5 \mathrm{mM}$ in $30 \%$ ethanol. The final ethanol concentration in the cell incubation was $0.3 \%$.

Cell incubation with $\mathrm{t}-\mathrm{BH}$ without or with substrates or inhibitors. During initial characterization of the enterocytes, we found that cells incubated at $37^{\circ} \mathrm{C}$ in the absence of substrates or oxidant maintained their viability for $30 \mathrm{~min}$ (the chosen time course of the experiments), and substantial loss of viability (40\%) was not evident until $120 \mathrm{~min}$. Moreover, we found that at $37^{\circ} \mathrm{C}, 6-\mathrm{AN}$ or $\mathrm{BCNU}$ alone has no direct cytotoxic effects on the cells. Enterocytes $\left(3.5-5 \times 10^{6}\right.$ cells $\left./ \mathrm{ml}\right)$ were incubated in $5-\mathrm{ml}$ or $10-\mathrm{ml}$ rotating round bottom flasks at $37^{\circ} \mathrm{C}$ as previously described $(12,13)$. The cells were preincubated for $5 \mathrm{~min}$ before addition of $300 \mu \mathrm{M} t \mathrm{BH}$. During the preincubation time, glucose, whenever present, was added to the cell suspensions at the specified concentrations. Cell viability was monitored throughout the incubation by trypan blue exclusion. At $0,5,15$, and $30 \mathrm{~min}, 0.5-\mathrm{ml}$ samples were transferred to Eppendorf tubes and cells were separated from the incubation medium by centrifugation in a microfuge. The media were saved on ice for $t \mathrm{BH}$ assay. In some experiments, $0.5 \mathrm{ml}$ of cell suspensions were directly treated with $0.5 \mathrm{M} \mathrm{KOH}$ containing $50 \%$ ( $\mathrm{vol} / \mathrm{vol}$ ) ethanol and 35\% (wt/vol) $\mathrm{CsCl}_{2}$ for measurements of cellular $\mathrm{NADH}$ and NADPH contents.

Diamide infusion into enterocyte suspensions. Enterocytes (3.5 $\times 10^{6}$ cells $/ \mathrm{ml}$ ) were incubated in rotating round bottom flasks as described above. Diamide-containing solutions at different concentrations were infused at $1 \mathrm{ml} / \mathrm{h}$ into the cell suspensions using a peristaltic pump (Pharmacia LKB Biotechnology Inc., Piscataway, NJ) equipped with $2 \mathrm{~mm}$ i.d. tubing as previously described (14). The concentrations of diamide were varied to give infusion rates of 0.02 to $1.0 \mathrm{nmol} / 10^{6}$ cells $/ \mathrm{min}$. Incubations were performed for $0,2,5$, or $10 \mathrm{~min}$. Initial experiments show that over the short duration of the incubations, there was no difference in cell viability at the different diamide doses, and at the low infusion rate, the maximum dilution of cell suspensions was $3 \%$. At the designated times, $0.5 \mathrm{ml}$ of cell suspension was removed and the cells were separated from the incubation mixture by centrifugation through a silicone-mineral oil mixture ( $6: 1$, by vol) layer into $10 \%$ TCA as described previously $(15,16)$. The acid supernatants and cell pellets were assayed for GSH and protein thiols, respectively.

Biochemical assays. Total acid-soluble thiols were measured by the method of Owens and Belcher (17). To verify that GSH was the major soluble thiol, GSH was also determined by HPLC (18). Protein thiols was determined in the TCA-precipitated cell pellets. The pellets were solubilized in $0.1 \mathrm{M} \mathrm{NaOH}$ and thiols were measured colorimetrically according to Ellman and Lysko (19). Pyridine nucleotides were determined by HPLC as previously described (20). Due to the instability of NADPH and NADH, ethanolic cell extracts were kept on ice and were analyzed within $2-3 \mathrm{~h}$ of sample preparation. $t \mathrm{BH}$ was determined spectrophotometrically according to Heath and Tappel (21). $t \mathrm{BH}$ was measured immediately after the end of the 30-min experiment, and samples kept on ice were stable as verified by standard $t \mathrm{BH}$ solutions processed under identical conditions. Cellular GSH redox enzyme activities were measured spectrophotometrically by enzyme-coupled assays for GSH peroxidase (22), GSSG reductase (23), and glucose 6-phosphate dehydrogenase (24). Protein was determined according to Bradford (25).

Statistical analyses. Data are expressed as means \pm SE. Analysis of variance and Student's $t$ test were used to determine significance of differences. $P<0.05$ was considered as significant.

Materials. 6-AN, D-glucose, diamide, and $t \mathrm{BH}$ were purchased from Sigma Chemical Co., St. Louis, MO. Carmustine (BCNU) was obtained from the Hospital Pharmacy, LSU Medical Center, Shreveport, LA. All other chemicals were of reagent grade and were purchased from local sources.

\section{Results}

Effect of glucose and inhibitors on metabolism of $\mathrm{t}-\mathrm{BH}$ in isolated enterocytes. To examine the role of glucose on intestinal metabolism of hydroperoxides, freshly isolated enterocytes were incubated with $t \mathrm{BH}$, without or with $10 \mathrm{mM}$ glucose. As shown in Fig. 2, $t$ BH elimination in intestinal cells under basal conditions was small. The initial rate of $t \mathrm{BH}$ elimination was $0.57 \pm 0.05 \mathrm{nmol} / 10^{6}$ cells per min, and the concentration of peroxide remaining at $30 \mathrm{~min}$ was $60-65 \%$ of the added dose $(300 \mu \mathrm{M})$. Addition of $10 \mathrm{mM}$ glucose caused a threefold increase in $t \mathrm{BH}$ elimination (initial rate $=1.74 \mathrm{nmol} / 10^{6}$ cells per min ), and by 30 min the amount of $t \mathrm{BH}$ remaining in the incubation medium was negligible (Fig. $2 A$ ). In the presence of $t \mathrm{BH}$, cell viability at 5 and $15 \mathrm{~min}$ incubation was not different from the control without oxidant. At $30 \mathrm{~min}, t \mathrm{BH}$ caused a $7-10 \%$ cell killing regardless of the glucose status. These results show that the catabolism of organic hydroperoxides in enterocytes is sensitive to exogenous glucose availability and that the observed glucose effect was not attributable to its cytoprotection against $t \mathrm{BH}$ injury.

A possible explanation of the glucose effect is that glucose stimulated NADPH production for GSSG reduction (Fig. 1). To test this suggestion and to determine whether the pentose phosphate pathway is a major source for NADPH generation, we incubated cells in the presence of glucose and 6-AN, a potent inhibitor of glucose 6-phosphate dehydrogenase (26), the rate-limiting step in the pathway $(10,27)$. The results in Fig. $2 B$ show that 6-AN ameliorated the stimulatory effect of glucose, supporting the view that exogenous glucose activates cellular NADPH production by the pentose phosphate shunt. 

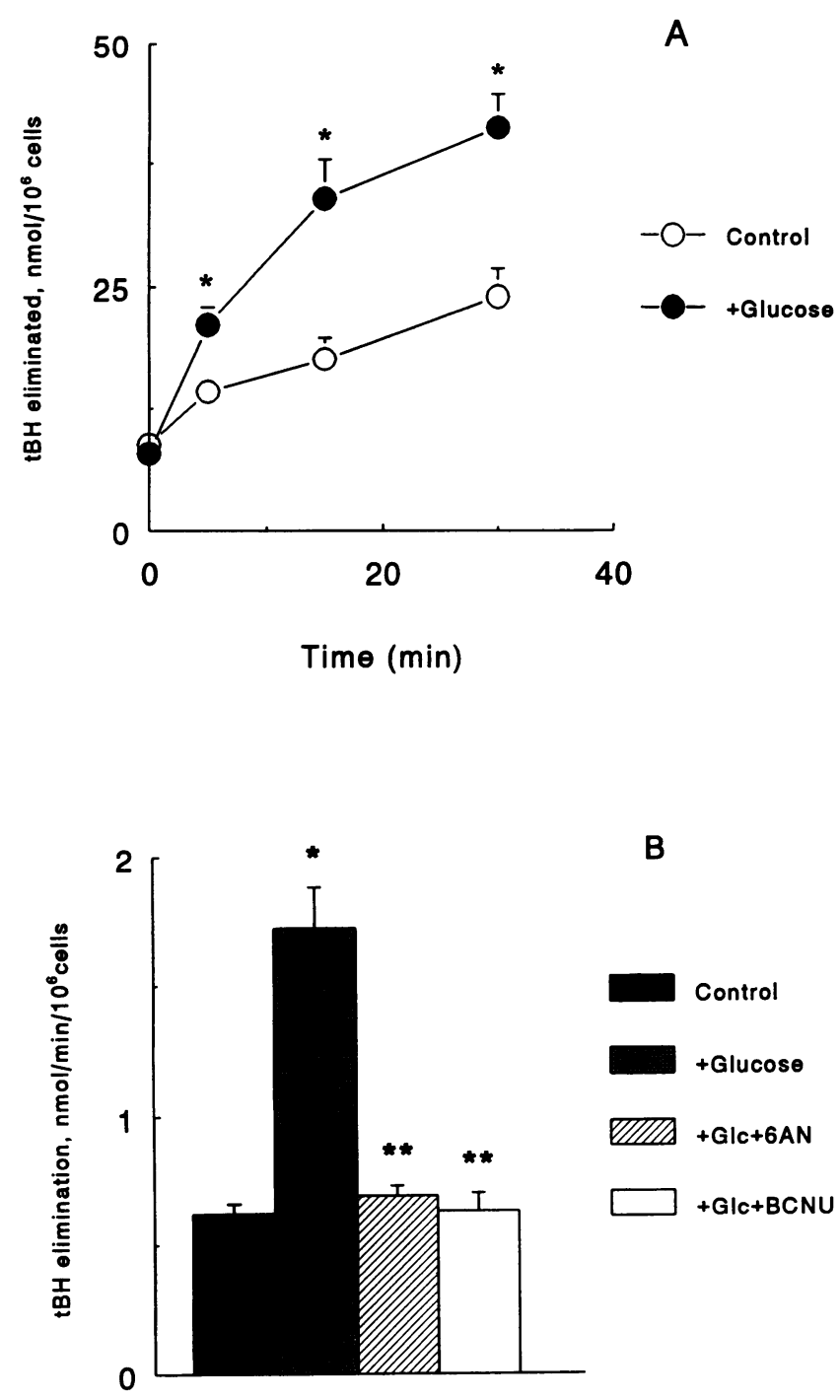

Figure 2. Glucose-dependent tert-butylhydroperoxide elimination in isolated enterocytes. Enterocytes $\left(3.5 \times 10^{6}\right.$ cells $\left./ \mathrm{ml}\right)$ were incubated for $0-30 \mathrm{~min}$ at $37^{\circ}$ in the absence or presence of $10 \mathrm{mM}$ glucose. In incubations with 6-AN $(0.5 \mathrm{mM})$ or BCNU $(50 \mu \mathrm{M})$, the cells were pretreated with the inihibitors for $20 \mathrm{~min}$ before the addition of glucose. The final $t \mathrm{BH}$ concentration was $300 \mu \mathrm{M}$. At the designated times, the incubation media were separated from the cells by centrifugation. The cell-free media were assayed for $t \mathrm{BH}$ spectrophotometrically (21). Results are mean \pm SE of five cell preparations for control, seven cell preparations for plus glucose alone, and eight cell preparations each for glucose plus 6-AN or glucose plus BCNU. $(A)$ Time course of $t \mathrm{BH}$ elimination. ${ }^{*} P<0.005$ vs control. (B) Initial rate of $t \mathrm{BH}$ elimination. ${ }^{*} P<0.001$ vs control; ${ }^{* *} P<0.001$ vs plus glucose.

To document that the glucose-induced increase in NADPH supported GSSG reduction, cells were pretreated with BCNU, an inhibitor of GSSG reductase (28). As shown in Fig. $2 B, B C N U$ treatment completely blocked the stimulatory effect of glucose, consistent with the interpretation that the NADPH generated from glucose was used to support $t \mathrm{BH}$ reduction.

To verify that cellular NADPH levels were, in fact, increased with glucose supplementation, we quantify the NADPH concentrations in control and glucose-supplemented cells. As
Table I. Effect of Exogenous Glucose on Reduced Pyridine Nucleotide Concentrations in Isolated Enterocytes

\begin{tabular}{|c|c|c|c|}
\hline \multirow[b]{2}{*}{ Incubation conditions } & & \multicolumn{2}{|c|}{ Reduced pyridine nucleotides } \\
\hline & & NADPH & NADH \\
\hline & $n$ & \multicolumn{2}{|c|}{ nmol/10 $0^{6}$ cells } \\
\hline Control (- glucose) & 5 & $0.57 \pm 0.05$ & $0.23 \pm 0.07$ \\
\hline$+10 \mathrm{mM}$ glucose & 7 & $1.62 \pm 0.40^{* \ddagger}$ & $0.89 \pm 0.06^{*}$ \\
\hline+ glucose $+300 \mu \mathrm{M} t \mathrm{BH}$ & 4 & $1.35 \pm 0.25^{*}$ & $0.89 \pm 0.11^{*}$ \\
\hline+ glucose $+0.5 \mathrm{mM} 6-\mathrm{AN}$ & 3 & $0.61 \pm 0.04$ & $0.88 \pm 0.10^{*}$ \\
\hline
\end{tabular}

Enterocytes $\left(5 \times 10^{6} \mathrm{cells} / \mathrm{ml}\right)$ were incubated for $15 \mathrm{~min}$ at $37^{\circ}$ in the absence or presence of glucose, $t \mathrm{BH}$, or 6-AN. Samples $(0.5 \mathrm{ml})$ were treated directly with $0.5 \mathrm{M} \mathrm{KOH}$ containing $50 \%$ ( $\mathrm{vol} / \mathrm{vol}$ ) ethanol and $35 \%(\mathrm{wt} / \mathrm{vol}) \mathrm{CsCl}_{2}$ for measurements of NADH and NADPH by HPLC (20). Results are mean \pm SE. $n=$ number of cell preparations. ${ }^{*} P<0.005$ vs control; ${ }^{\ddagger} P<0.005$ vs glucose +6 -AN.

shown in Table I, the total reduced pyridine nucleotide pool in enterocytes was $\sim 0.8 \mathrm{nmol} / 10^{6}$ cells, of which $70 \%$ was NADPH. In the presence of glucose, the NADPH and NADH levels were significantly elevated (three- and fourfold, respectively, Table I), consistent with promotion of the cellular reductant pool in response to glucose availability. These concentrations remained essentially unchanged in the presence of $t \mathrm{BH}$, indicating that exogenous glucose can maintain steady-state reductant levels during an oxidant load. The increase in cell NADPH was ameliorated by 6-AN (Table I), thereby confirming that the glucose-induced increase in NADPH occurred principally by stimulation of the pentose phosphate pathway. The stimulation of NADPH production with exogenous glucose further suggests that the flux of endogenous glucose through the pentose phosphate shunt is low, consistent with a preferential oxidation of glucose in aerobic glycolysis.

An enhancement of $t \mathrm{BH}$ loss by exogenous glucose implicates a role for nutritional status on hydroperoxide elimination. To test this suggestion, we compared the rates of $t \mathrm{BH}$ loss in cells isolated from the proximal intestine of fed and 24-h fasted rats. Fig. 3 shows that the initial rate of $t \mathrm{BH}$ elimination in cells from fasted animals was $50 \%$ lower than the rate in fed controls. The metabolic rate in glucose-depleted cells was significantly stimulated by exogenous glucose, and to an extent greater than cells from fed rats (Fig. 3). These results are therefore consistent with a compromised metabolic capacity in the fasted intestine.

To further investigate the intestinal detoxication capacity for hydroperoxides, we measured cellular activities of the key enzymes that are central to the function of the GSH redox cycle. The results in Table II show that the activities of glucose 6phosphate dehydrogenase and GSSG reductase were, respectively, 7.1 and 2.8 times lower than the activity of GSH peroxidase. This suggests that the supply of NADPH and its subsequent use for GSSG reduction could limit GSH redox cycle function in hydroperoxide metabolism in enterocytes.

Quantification of NADPH supply rate by diamide infusion. To quantify the cellular rate of NADPH supply, we used an approach that was previously established for hepatocytes (14). Basically, the method involves controlled infusions of diamide, a thiol oxidant, into cell suspensions and measuring the ability 


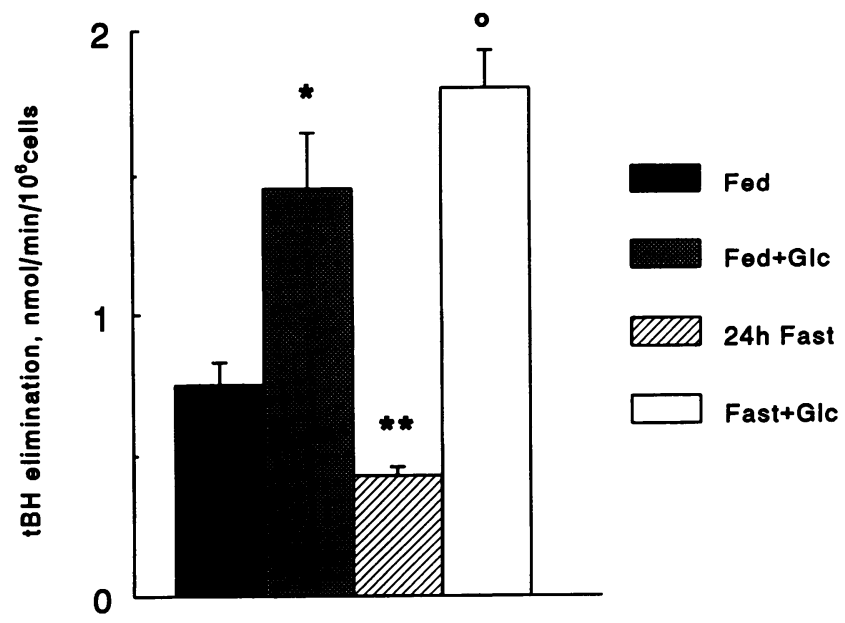

Figure 3. Comparison of $t \mathrm{BH}$ elimination rate without or with glucose in isolated enterocytes from fed and fasted rats. Intestinal cells were isolated from proximal intestine of fed rats or rats fasted for $24 \mathrm{~h}$. Enterocytes $\left(3.5 \times 10^{6}\right.$ cells $\left./ \mathrm{ml}\right)$ were incubated without or with glucose as described in Fig. 1. Results are mean \pm SE of four cell preparations each for fed and fasted rats. ${ }^{*} P<0.05 ;{ }^{*} P<0.01$ vs fed control; ${ }^{\circ} P<0.001$ vs fasted control.

of the cells to maintain constant GSH. According to Fig. 1, the NADPH supply rate for hydroperoxide elimination can be determined by the rate of GSSG reduction to maintain a steadystate cellular GSH pool. Based on this reasoning, the rate at which the cell is unable to maintain steady-state GSH levels will represent the maximal NADPH supply rate, and the diamide infusion rate at this "break point" is termed the critical infusion rate (14). Thus, the determination of the critical diamide infusion rates in control and glucose-supplemented cells will provide reasonable estimates of the NADPH supply rate under glucose-depleted or glucose-replete conditions.

Infusion of diamide in control cell suspensions caused a dose- and time-dependent decrease in cell GSH (Fig. 4). Constant cell GSH was maintained at a low diamide infusion of $0.02 \mathrm{nmol} / \mathrm{min}$ per $10^{6}$ cells, but the GSH pool progressively decrease at higher infusion rates of $0.08 \mathrm{nmol} / \mathrm{min}$ per $10^{6}$ cells or greater. This failure to preserve constant cell GSH with increasing diamide concentrations indicates that the rate of GSH oxidation exceeded that of GSSG reduction. Concurrent with the decreases in cell GSH with increasing diamide doses were significant losses in protein thiols (Table III), suggesting that oxidation of protein sulhydryls occurred in parallel with substantial oxidation of cell GSH.

The addition of $10 \mathrm{mM}$ glucose resulted in significant preservation of the cellular GSH pool at diamide doses of $0.02-$ $0.25 \mathrm{nmol} / \mathrm{min}$ per $10^{6}$ cells (Fig. 5). Substantial loss of GSH were detectable only at $10 \mathrm{~min}$ at infusion rates of $0.5 \mathrm{nmol} /$ min per $10^{6}$ cells, and at $5 \mathrm{~min}$ and $10 \mathrm{~min}$ at diamide infusion of $1.0 \mathrm{nmol} / \mathrm{min}$ per $10^{6}$ cells (Fig. 5). At the low doses of diamide $\left(0.02-0.25 \mathrm{nmol} / \mathrm{min}\right.$ per $10^{6}$ cells $)$, protein thiols were well preserved, and even at higher doses of diamide (0.5$1.0 \mathrm{nmol} / \mathrm{min}$ per $10^{6}$ cells $)$, the losses of protein thiols were small as compared to controls (Table III). These results are consistent with glucose supporting GSH regeneration from GSSG, thereby maintaining cell GSH and preserving protein thiol levels.
Table II. Activities of GSH Peroxidase, GSSG Reductase, and Glucose 6-Phosphate Dehydrogenase in Enterocytes

\begin{tabular}{lcc}
\hline \multicolumn{1}{c}{ Enzymes } & & \\
\hline & $n$ & nmolmin per $m g$ protein \\
GSH peroxidase & 6 & $75.6 \pm 8.2$ \\
GSSG reductase & 6 & $26.9 \pm 2.6$ \\
Glucose 6-phosphate dehydrogenase & 6 & $10.6 \pm 0.9$ \\
\hline
\end{tabular}

Cellular GSH redox cycle enzymes were measured spectrophotometrically by enzyme-coupled assays for GSH peroxidase (22), GSSG reductase (23), and glucose 6-phosphate dehydrogenase (24). Protein concentration per $10^{6}$ cells was $1.16 \pm 0.08 \mathrm{mg}$. Results are mean \pm SE. $n=$ number of preparations.

To verify that the promotion of GSSG reduction occurred through enhanced supply of NADPH, diamide was infused into glucose-supplemented cell suspensions treated with 6-AN. The results show that 6 -AN-treated cells were unable to maintain constant GSH after $5 \mathrm{~min}$ at diamide infusion rates between 0.25 and $1.0 \mathrm{nmol} / \mathrm{min}$ per $10^{6}$ cells (Fig. 6). Substantial losses in protein thiol contents paralleled the decreases in cell GSH (Table III). Collectively, these results support the interpretation that the maintenance of cell GSH by glucose occurred via stimulation of NADPH production by the pentose phosphate pathway for the reduction of GSSG generated from diamide oxidation of GSH. Furthermore, the correspondence of protein thiol changes with those of cell GSH indicates a close relationship between maintenance of cell GSH with preservation of protein thiol status.

To determine the maximal NADPH supply rate, the data from Figs. 4-6 at 10 min time was replotted to relate changes in cell GSH with the different diamide infusion rates. From this relationship (Fig. 7), we estimated the critical diamide infusion rate, i.e., the rate at which cell GSH fell. In the absence of added substrate, the diamide-induced decrease in cell GSH occurred at an infusion rate of $0.05 \mathrm{nmol} / \mathrm{min}$ per $10^{6}$ cells (Fig. 7). In cells supplemented with glucose, the critical diamide infusion rate was 10 -fold higher at $0.5 \mathrm{nmol} / \mathrm{min}$ per $10^{6}$ cells (Fig. 7 ), consistent with glucose stimulation of NADPH supply to maintain high cell GSH. The addition of glucose to a final concentration of $20 \mathrm{mM}$ was without additional effects (data not shown), indicating that maximal reductant supply was achieved with $10 \mathrm{mM}$ glucose. The shift to a higher critical infusion rate in the presence of glucose was prevented by 6-AN (Fig. 7), consistent with an inhibition of glucose use for NADPH production.

The impact of glucose on GSH and protein thiols in cells with elevated GSH contents was evaluated by determining the responses of GSH-supplemented cells to different diamide loads without or with added glucose. Cells were preloaded with 1 $\mathrm{mM}$ GSH for $20 \mathrm{~min}$ at $37^{\circ} \mathrm{C}$, and washed once. Under these conditions, cell GSH levels were $4.0 \mathrm{nmol} / 10^{6}$ cells. Thereafter, cells were resuspended in the absence or presence of $10 \mathrm{mM}$ glucose and were infused with varying doses of diamide as described above. The relationship of cell GSH with diamide doses is shown in Fig. 8. The critical diamide infusion rate in cells supplemented with GSH alone without glucose was similar to that in control cells $\left(0.05 \mathrm{nmol} / \mathrm{min}\right.$ per $10^{6}$ cells $)$. In com- 


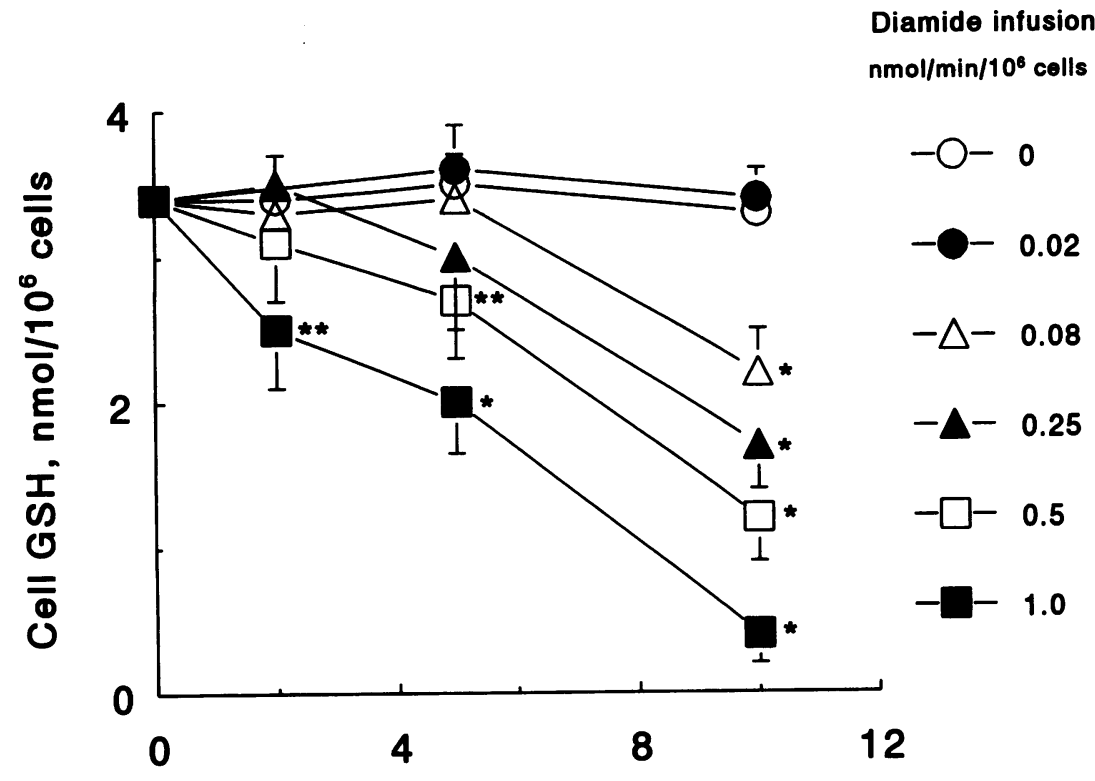

Time, $\min$ parison, cells supplemented with GSH plus glucose maintained high cell GSH at all diamide doses with the critical infusion rate occurring at $1.0 \mathrm{nmol} / \mathrm{min}$ per $10^{6}$ cells (Fig. 8). These data suggest that, while GSH supplementation increases cell GSH, this GSH pool will be rapidly depleted under oxidant stress unless a source for GSSG reduction is made available, such as by glucose through increased NADPH supply. In contrast, protein thiols in GSH-supplemented cells were significantly higher than controls at high doses of diamide $(0.25-1.0$ $\mathrm{nmol} / \mathrm{min}$ per $10^{6}$ cells , and were essentially unchanged when glucose was also present (Table III). Taken together, these results show that during an oxidant stress, protein thiols are maintained at the expense of cell GSH and that the preservation of the protein thiol status can be further sustained by increasing cellular GSH levels with a combination of exogenous GSH and glucose supplementation.

\section{Discussion}

Our previous studies have shown that the availability of GSH is a key determinant of the intestinal metabolism of lipid hydroperoxides $(6,7)$. In the current study we provided evidence for a role of glucose in the elimination of $t \mathrm{BH}$ by rat small intestinal cells. The results show that exogenous glucose supplementation promoted $t \mathrm{BH}$ loss from the incubation medium, consistent with enhanced hydroperoxide metabolism. Mechanistically, the glucose effect appears to be mediated through stimulation of the pentose phosphate shunt activity to increase NADPH supply for GSSG reduction.

Several lines of evidence are consistent with this interpretation. First, the addition of glucose was directly accompanied by increases in cell NADPH levels concurrent with increases in the rate of hydroperoxide elimination. Second, the amelioration

Table III. Effect of Diamide Infusion on Protein Thiol Contents in Isolated Enterocytes

\begin{tabular}{|c|c|c|c|c|c|}
\hline Diamide dose & Control & Glc & $\mathrm{Glc}+6 \mathrm{AN}$ & GSH & $\mathrm{GSH}+\mathrm{Glc}$ \\
\hline nmol/10 cells per min & (4) & (5) & (5) & (4) & (4) \\
\hline 0 & $40.9 \pm 3.8$ & $40.8 \pm 3.0$ & $40.6 \pm 3.6$ & $40.8 \pm 1.7$ & $38.5 \pm 6.2$ \\
\hline 0.02 & $40.0 \pm 2.0$ & $39.4 \pm 4.5$ & $38.0 \pm 2.0$ & $39.0 \pm 2.0$ & $36.0 \pm 4.0$ \\
\hline 0.08 & $28.6 \pm 4.5$ & $34.9 \pm 2.0$ & $30.6 \pm 4.9$ & $35.2 \pm 4.3$ & $36.0 \pm 2.7$ \\
\hline 0.25 & $22.1 \pm 3.3$ & $32.0 \pm 3.0^{*}$ & $21.0 \pm 3.3^{\ddagger}$ & $29.0 \pm 3.0 *$ & $33.0 \pm 3.0^{8}$ \\
\hline 0.5 & $16.5 \pm 3.0$ & $28.4 \pm 4.6^{*}$ & $19.0 \pm 3.0^{\| \prime}$ & $27.5 \pm 4.6^{*}$ & $32.2 \pm 4.6 *$ \\
\hline 1.0 & $7.8 \pm 2.0$ & $25.3 \pm 4.6^{*}$ & $13.0 \pm 2.0^{\ddagger}$ & $23.0 \pm 3.0 * 1$ & $31.0 \pm 4.4 *$ \\
\hline
\end{tabular}

Enterocytes $\left(3.5 \times 10^{6} \mathrm{cells} / \mathrm{ml}\right)$ were infused with diamide $\left(0.02-1.0 \mathrm{nmol} / \mathrm{min}\right.$ per $10^{6}$ cells) for $10 \mathrm{~min}$ as described in Methods. Cells were centrifuged through a silicone-mineral oil mixture into $10 \% \mathrm{TCA}$ and the cell pellets were assayed for protein thiols (19). Results are mean \pm SE of the number of preparations in parentheses. ${ }^{*} P<0.005$ and ${ }^{\ddagger} P<0.005$ and ${ }^{\S} P<0.01$ vs control; $" \| P<0.01$ vs Glc; ${ }^{\natural} P<0.05$ vs GSH + Glc. Glc, glucose. 


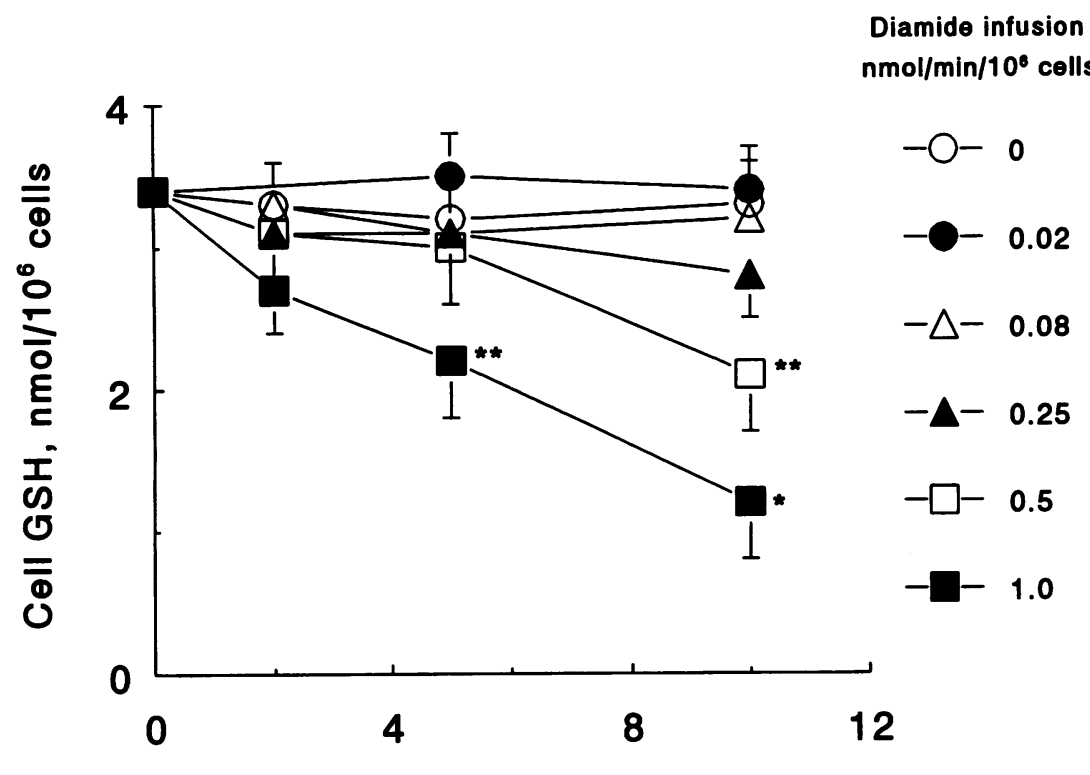

Time, $\min$

of the stimulatory effects of glucose by inhibition of either $(a)$ glucose 6-phosphate dehydrogenase with 6-AN (26) or $(b)$ GSSG reductase with BCNU (28) is consistent with an enhanced glucose flux through the pentose phosphate shunt for NADPH production and the subsequent use of NADPH by GSSG reductase-catalyzed regeneration of GSH. Third, a low cellular glucose 6-phosphate dehydrogenase activity as compared to GSH peroxidase and GSSG reductase suggests a potential limitation for GSSG reduction at the level of NADPH supply. Finally, the maintenance of constant cell GSH levels with glucose during steady-state infusion of a thiol oxidant is consistent with continuous regeneration of GSH from GSSG.
Figure 5. Diamide-induced depletion of cell GSH in glucose-supplemented cells. Intestinal cell isolation and incubations with diamide were as described in Fig. 4. In these experiments, the incubation medium also contained $10 \mathrm{mM}$ glucose. Results are mean \pm SE of five cell preparations. $* P<0.005$ and $* * P<0.05$ vs control (without diamide).
The finding that the endogenous rate of $t \mathrm{BH}$ elimination was low and that this rate increased markedly with exogenous glucose suggests that mucosal detoxication of hydroperoxides would subscribe to regulation by the luminal glucose concentration. Our results on fed and fasted animals are consistent with a reliance of the cellular glucose status on the nutritional state of the animal. In hepatocytes, the basal rate of $t \mathrm{BH}$ eliminiation is high $(29,30)$, and this hepatic rate is minimally affected by exogenous glucose (14). The difference in responses to exogenous glucose between enterocytes and hepatocytes may be explained by the fact that the liver has an intracellular glucose source, namely glycogen. Hence, the control of substrate supply

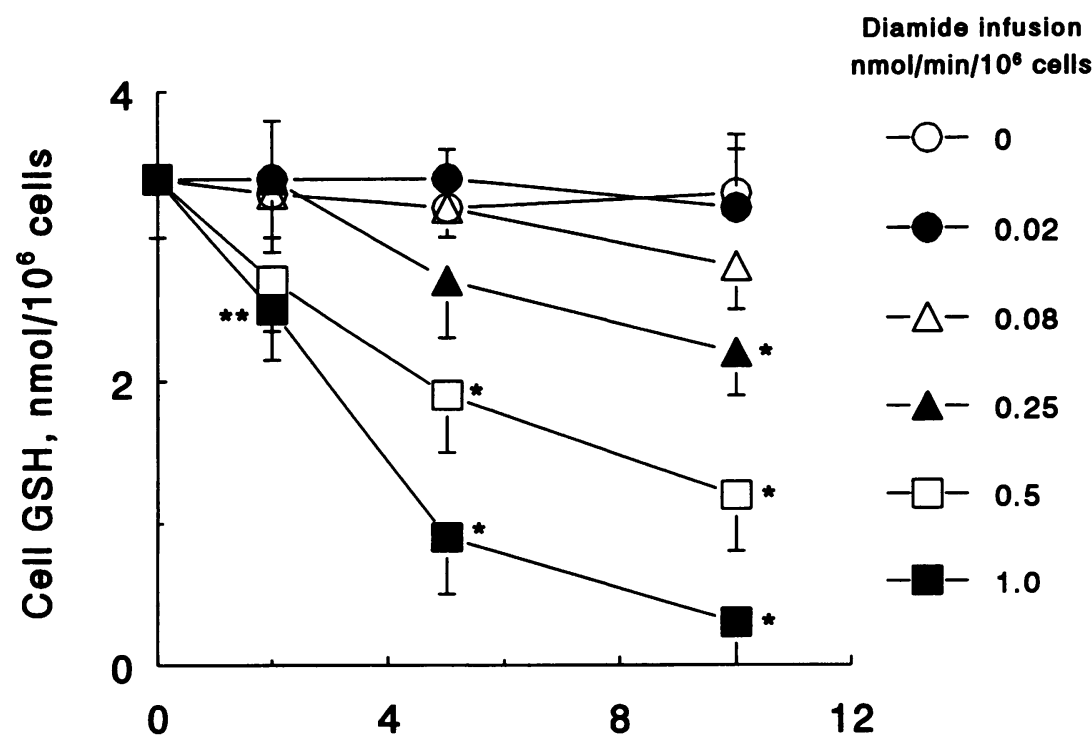

Time, $\min$
Figure 6. Diamide-induced depletion of cell GSH in 6-AN-treated cells. Intestinal cell isolation and incubations with diamide were performed as described in Fig. 4. In these experiments, cells were pretreated with 6-AN for 20 min before addition of $10 \mathrm{mM}$ glucose. Results are mean $\pm \mathrm{SE}$ of five cell preparations. $* P<0.005$ and $* * P<0.05$ vs control (without diamide). 


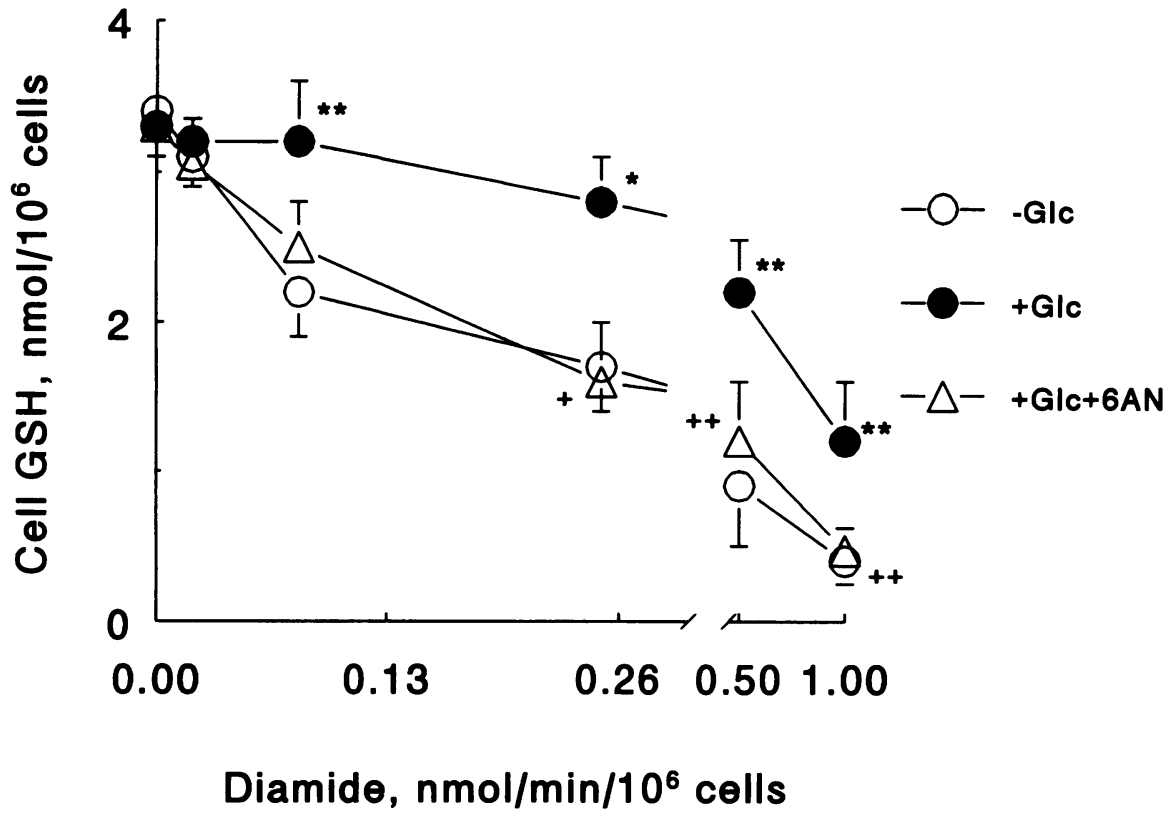

Figure 7. Dependence of cell GSH on diamide infusion rates. The data at 10 min time point from Figs. 4-6 were plotted to express cell GSH concentrations as a function of diamide infusion rates. In control $(-\mathrm{Glc})$ and Glc plus 6-AN-treated cells, GSH was significantly decreased by diamide at $0.08-1.0$ $\mathrm{nmol} / 10^{6}$ cells per min $(P<0.05)$. In the presence of glucose, cell GSH was significantly lower at 0.5 and $1.0 \mathrm{nmol} / 10^{6}$ cells per min diamide $(P<0.05)$. For comparisons of control $(-\mathrm{Glc})$ vs Glc, $* P<0.005$ and $* * P<0.05$. For comparisons of Glc vs $\mathrm{Glc}+6 \mathrm{AN},{ }^{+} P<0.005$ and ${ }^{++} P<0.05$. Glc, glucose. in liver and intestine could determine organ-specific regulation of hydroperoxide detoxication.

It is significant that increased glucose supply supports constant steady-state levels of GSH at increasing oxidant loads since the maintenance of cell GSH sustains the function of the GSH redox cycle to facilitate the rapid and efficient removal of toxic peroxides (9, Fig. 1). In addition, the preservation of a constant GSH pool prevents oxidant-induced oxidation of protein thiols during oxidative stress. This latter interpretation is consistent with our observations that $(a)$ oxidation of protein thiols occurred at the expense of cell GSH, and $(b)$ supplementation of glucose-replete cells with exogenous GSH better maintains cell GSH at high oxidant doses and thereby maintains the protein thiol status. The preservation of homeostatic thiol/ disulfide status of proteins is critical to the cellular function of many enzymes whose activities are dependent on critical thiol groups for catalysis (8).

In previous studies, Tribble and Jones have extensively characterized the diamide-induced GSH redox cycle model for estimating NADPH supply rate in isolated hepatocytes (14). In the current study, the rate of NADPH supply in isolated enterocytes can similarly be estimated using this approach. The method relies on the simple principle that, in the presence of a steadystate oxidant load, constant cell GSH levels can be maintained if the rate of GSH oxidation by the oxidant is matched by the rate of GSSG reduction by NADPH. Thus, at the point where GSH oxidation exceeds GSSG reduction, maximal supply of NADPH is reached. Experimentally this critical point is reached when cell GSH falls in response to an oxidant load. Our results show that the maximal NADPH supply rate in the absence of

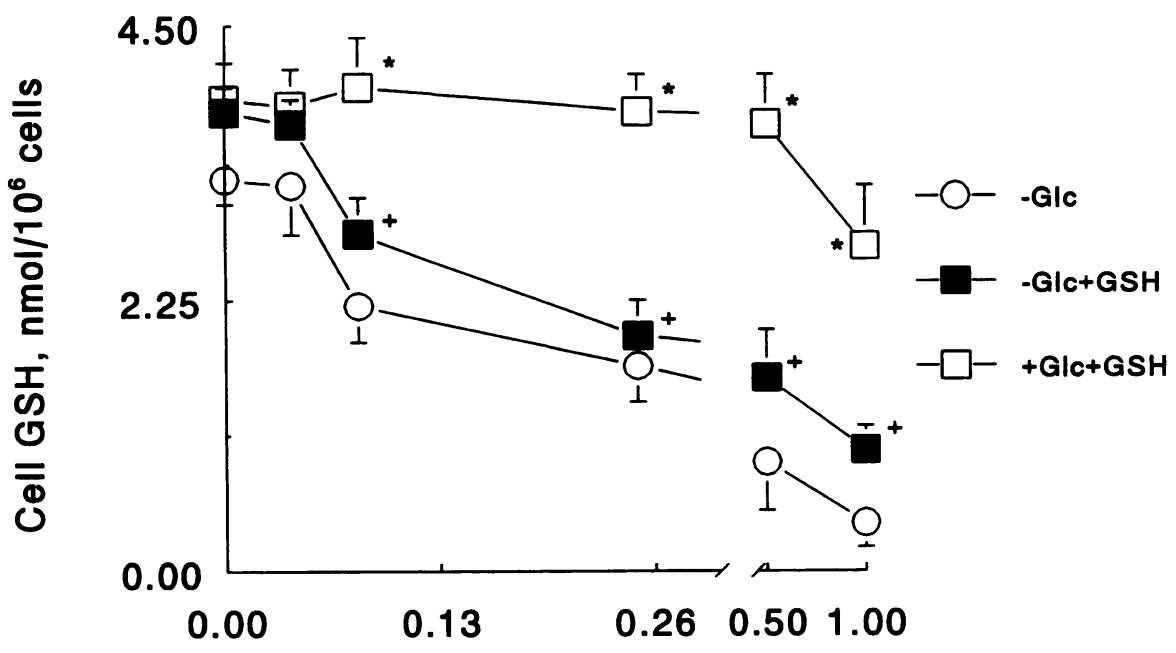

Diamide, $\mathrm{nmol} / \mathrm{min} / 10^{6}$ cells
Figure 8. Dependence of cell GSH on diamide infusion rates: effect of GSH without or with glucose. Intestinal cells were prepared from fed rats as described (11). Enterocytes $\left(3.5 \times 10^{6}\right.$ cells $\left./ \mathrm{ml}\right)$ were preincubated with $1 \mathrm{mM} \mathrm{GSH}$ for $20 \mathrm{~min}$ at $37^{\circ} \mathrm{C}$. Cells were washed and resuspended in GSHfree buffer without or with $10 \mathrm{mM}$ glucose. Diamide infusions were performed as described in Methods. GSH was assayed as described (18), and the values were expressed as a function of diamide infusion rates. $\mathrm{Re}$ sults are mean $\pm \mathrm{SE}$ of four cell preparations. In control ( - Glc) and GSH-treated cells, GSH was significantly decreased by diamide at $0.08-1.0 \mathrm{nmol} / 10^{6}$ cells per min $(P$ $<0.05$ ). In the presence of GSH plus glucose, cell GSH was significantly lower at 1.0 nmol $/ 10^{6}$ cells per min diamide $(P<0.05)$. For comparisons of control $(-\mathrm{Glc})$ vs Glc $+\mathrm{GSH},{ }^{*} P<0.005$. For comparisons of GSH vs Glc + GSH, ${ }^{+} P<0.005$. 
substrates $\left(0.05 \mathrm{nmol} / \mathrm{min}\right.$ per $10^{6}$ cells $)$ is 10 -fold lower than the maximal reducant supply rate achieved with exogenous glucose $\left(0.5-1.0 \mathrm{nmol} / \mathrm{min}\right.$ per $10^{6}$ cells $)$, supporting the view that NADPH generation is regulated by glucose availability. Previous estimates of NADPH supply in hepatocytes were in the range of $5-8 \mathrm{nmol} / \mathrm{min}$ per $10^{6}$ cells $(14,31-34)$. Thus, it appears that even at maximum production rate, the availability of NADPH in intestinal cells for hydroperoxide metabolism will be 5-10 times lower than in liver, suggesting a severely compromised capacity of the small intestine for handling high concentrations of hydroperoxides.

Interestingly, our results show that the basal rate of NADPH supply was lower than the rate of $t \mathrm{BH}$ removal, in agreement with the findings in hepatocytes (14). In control cells, the rate of $t \mathrm{BH}$ loss was about 10 -fold faster than the rate of reductant supply. In the presence of glucose, in which NADPH supply was maximal, the rate of $t \mathrm{BH}$ removal was still twofold faster than reductant supply. This rate difference may be due, in part, to some inherent imprecision in rate determinations associated with the current experimental approaches. In this study, we determined the rate of $t \mathrm{BH}$ metabolism by measuring the amount of hydroperoxide remaining while we estimated NADPH supply rate from cell GSH loss. Alternatively, the results could also implicate involvement of another reductant source for hydroperoxide metabolism that is independent of the function of the GSH redox cycle. Our previous studies with isolated hepatocytes suggest that NADH could serve as a reductant source for hydroperoxide metabolism (30). In that study, we found that lactate promoted the rate of $t \mathrm{BH}$ elimination with concomitant generation of pyruvate $(30)$, consistent with a role for NADH-catalyzed reduction of hydroperoxide. In the current study, glucose increased the enterocyte NADH pool by fourfold (Table I), but, in contrast to hepatocytes, we found that lactate did not support $t \mathrm{BH}$ elimination in enterocytes (Aw, unpublished observations). Thus, while glucose stimulated cellular NADH concentrations, the increase in this reductant pool was probably not associated with promotion of intestinal $t \mathrm{BH}$ reduction. It is significant that NADPH accounts for $\sim 50 \%$ of the rate of hydroperoxide elimination, supporting a role for the intestinal GSH peroxidase/GSSG reductase system in the quantitative detoxication of hydroperoxides. However, the possible involvement of a GSH peroxidase/GSSG reductase-independent pathway for intestinal hydroperoxide elimination is intriguing, and warrants further investigation.

In summary, we have shown that endogenous hydroperoxide elimination in intestinal cells is enhanced by exogenous glucose supplementation. The mechanism of regulation appears to involve glucose-mediated generation of NADPH through increased pentose phosphate shunt activity, use of NADPH in the maintenance of cell GSH, and promotion of hydroperoxide elimination. This sensitivity of hydroperoxide reduction to the nutrient status of enterocytes suggests that reductant supply by the pentose phosphate shunt may overall be rate limiting for intestinal hydroperoxide detoxication. The integration of glucose metabolism with peroxide catabolism and the increase of cell GSH by direct exogenous GSH underscores a potential for nutrient supplementation in the enhancement of GSH-dependent detoxication of exogenously supplied or endogenously generated hydroperoxides by the small intestine. Since oxidative injury to the epithelium has been implicated in the pathogenesis of various intestinal disorders $(35,36)$, and hydroperoxides are known to be cytotoxic and mutagenic $(36,37)$, the promotion of cellular GSH-dependent mechanisms could reduce the risk for development of intestinal pathologies.

\section{Acknowledgments}

This study was supported by the National Institute of Diabetes and Digestive Kidney Diseases grant DK-44510. T.Y. Aw is a recipient of an American Heart Association Established Investigatorship Award.

\section{References}

1. Hagen, T. M., T. Y. Aw, and D. P. Jones. 1988. Glutathione uptake and protection against oxidative injury in isolated kidney cells. Kidney Int. 34:74-81.

2. Lash, L. H., T. M. Hagen, and D. P. Jones. 1986. Exogenous glutathione protects intestinal epithelial cells from oxidative injury. Proc. Natl. Acad. Sci. USA. 83:4641-4645.

3. Hagen, T. M., L. A. Brown, and D. P. Jones. 1986. Protection against paraquat-induced injury by exogenous GSH in pulmonary alveolar type II cells. Biochem. Pharmacol. 35:4537-4542.

4. Andreoli, S. P., C. P. Mallett, and J. M. Bergstein. 1986. Role of glutathione in protecting endothelial cells against hydrogen peroxide oxidant injury. J. Lab. Clin. Med. 108:190-198.

5. Geiger, P. G., J. P. Thomas, and A. W. Girotti. 1991. Lethal damage to murine L1210 cells by exogenous lipid hydroperoxides: protective role of glutathione-dependent selenoperoxidases. Arch. Biochem. Biophys. 288:671-680.

6. Aw, T. Y., M. W. Williams, and L. Gray. 1992. Absorption and lymphatic transport of peroxidized lipids by rat small intestine in vivo: role of mucosal GSH. Am. J. Physiol. 262:G99-G106.

7. Aw, T. Y., and M. W. Williams. 1992. Intestinal absorption and lymphatic transport of peroxidized lipids in rats: effect of exogenous GSH. Am. J. Physiol. 263:G665-G672.

8. Brigelius, R. 1985. Mixed disulfides: biological functions and increase in oxidative stress In Oxidative Stress. H. Sies, editor. Academic Press. New York. 243-272.

9. Chance, B., H. Sies, and A. Boveris. 1979. Hydroperoxide metabolism in mammalian organs. Physiol. Rev. 59:5227-5605.

10. Bousiguone, A., and A. DeFlora. 1972. Regulatory properties of glucose 6-phosphate dehydrogenase. Curr. Top. Cell. Reg. 6:21-62.

11. Masola, B., and D. F. Evered. 1984. Preparation of rat enterocyte mitochondria. Biochem. J. 218:441-447.

12. Aw, T. Y., and D. P. Jones. 1982. Secondary bioenergetic hypoxia: inhibition of sulfation and glucuronidation reactions in isolated hepatocytes at low $\mathrm{O}_{2}$ concentrations. J. Biol. Chem. 257:8997-9004.

13. Aw, T. Y., and D. P. Jones. 1985. ATP concentration graduents in cytosol of liver cells during hypoxia. Am. J. Physiol. 249:C385-C392.

14. Tribble, D. L., and D. P. Jones. 1990. Oxygen dependence of oxidative stress: rate of NADPH supply for maintaining the GSH pool during hypoxia. Biochem. Pharmacol. 39:729-736.

15. Andersson, B. S., and D. P. Jones. 1987. Use of digitonin fraction to determine mitochondrial transmembrane ion distribution in cells during anoxia. Anal. Biochem. 146:164-172.

16. Aw, T. Y., B. S. Andersson, and D. P. Jones. 1987. Mitochondrial transmembrane ion distribution during anoxia. Am. J. Physiol. 252:C356-C361.

17. Owens, C. W. I., and R. V. Belcher. 1965. A colorimetric micromethod for the determination of glutathione. Biochem. J. 94:705-711.

18. Reed, D. J., J. R. Babson, P. W. Beatty, A. E. Brodie, W. W. Ellis, and D. W. Potter. 1980. High-performance liquid chromatography analysis of nanomole levels of glutathione, glutathione disulfide, and related thiols and disulfides. Anal. Biochem. 106:55-62.

19. Ellman, G., and H. Lysko. 1979. A precise method for the determination of whole blood and plasma sulfhydryl groups. Anal. Biochem. 93:98-102.

20. Jones, D. P. 1981. Determination of pyridine dinucleotides in cell extracts by high-performance liquid chromatography. J. Chromatogr. 225:446-449.

21. Heath, R. L., and A. L. Tappel. 1976. A new sensitive assay for the measurement of hydroperoxides. Anal. Biochem. 76:184-191.

22. Tappel, A. L. 1978. Glutathione peroxidase and hydroperoxides. Methods Enzymol. 52:506-513.

23. Goldberg, D. M., and R. J. Spooner. 1983. Glutathione reductase. Methods Enz. Analysis. 3:258-264.

24. Deutsch, J. 1983. Glucose 6-phosphate dehydrogenase. Methods Enz. Analysis. 3:190-196.

25. Bradford, M. M. 1976. A rapid and sensitive method for the quantitation 
of microgram quantities of protein utilizing the principle of protein-dye binding. Anal. Biochem. 72:248-254.

26. Rush, G. F., and D. Alberts. 1986. tert-Butyl hydroperoxide metabolism and stimulation of the pentose phosphate pathway in isolated rat hepatocytes. Toxicol. Appl. Pharmacol. 85:324-331.

27. Eggleston, L. V., and H. A. Krebs. 1974. Regulation of the pentose phosphate cycle. Biochem. J. 138:425-435.

28. Babson, J. R., and D. J. Reed. 1978. Inactivation of glutathione reductase by 2 -chloroethylnitrosourea-derived isocyanates. Biochem. Biophys. Res. Commun. 83:754-762.

29. Tribble, D. L., D. P. Jones, and D. E. Edmondson. 1988. Effect of hypoxia on tert-butyl hydroperoxide-induced oxidative injury in hepatocytes. Mol. Pharmacol. 34:413-420.

30. Kowalski, D. P., T. Y. Aw, and D. P. Jones. 1992. Postanoxic oxidative injury in rat hepatocytes: lactate-dependent protection against tert-butyl hydroperoxide. Free Radical Biol. \& Med. 12:205-212.
31. Weigl, K., and H. Sies. 1977. Drug oxidations dependent on cytochrome P-450 in isolated hepatocytes. Eur. J. Biochem. 77:401-408.

32. Thurman, R. G., and P. Scholz. 1973. Interaction of mixed-function oxidation with biosynthetic processes. Eur. J. Biochem. 38:73-78.

33. Waydhas, C., K. Weigl, and H. Sies. 1978. The disposition of formaldehyde and formate arising from drug $\mathrm{N}$-demethylation dependent on cytochrome P-450 in hepatocytes and in perfused rat liver. Eur. J. Biochem. 89:143-150.

34. Erickson, R. R., and J. L. Holtzman. 1976. Kinetic studies on the metabolism of ethylmorphine by isolated hepatocytes from adult rats. Biochem. Pharmacol. 25:1501-1506.

35. Grisham, M. B., and D. N. Granger. 1988. Neutrophil-mediated mucosal injury. Role of reactive oxygen metabolites. Dig. Dis. Sci. 33:6S-15S.

36. Ames, B. 1983. Dietary carcinogens and anticarcinogens. Science Wash. DC 221:1256-1263.

37. Coles, B., and B. Ketterer. 1990. The role of glutathione and transferases in chemical carcinogenesis. Crit. Rev. Biochem. Mol. Biol. 25:47-70. 